Review article

\title{
Adrenergic signaling in heart failure and cardiovascular aging
}

\author{
Gaetano Santulli ${ }^{\mathrm{a}, *}$, Guido Iaccarino ${ }^{\mathrm{b}, *}$ \\ a College of Physicians \&'Surgeons, Columbia University Medical Center, New York, NY, USA \\ ${ }^{\mathrm{b}}$ Division of Internal Medicine, Department of Medicine and Surgery, University of Salerno, Italy
}

\section{A R T I C L E I N F O}

\section{Article history:}

Received 4 March 2016

Received in revised form 23 March 2016

Accepted 25 March 2016

Available online xxx

\section{Keywords:}

Sympathetic nervous system

Beta adrenergic receptors

Aging

Multimorbidity

Cardiovascular system

$\mathrm{G}$ protein-coupled receptor kinases

Heart failure

\begin{abstract}
A B S T R A C T
Both cardiovascular disease and aging are associated with changes in the sympathetic nervous system. Indeed, mounting evidence indicates that adrenergic receptors are functionally involved in numerous processes underlying both aging and cardiovascular disorders, in particular heart failure. This article will review the pathophysiological role of the sympathetic nervous system in heart failure and cardiovascular aging.
\end{abstract}

(c) 2016 Elsevier Ireland Ltd. All rights reserved.

\section{Contents}

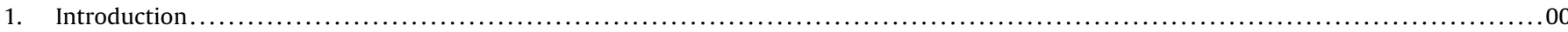

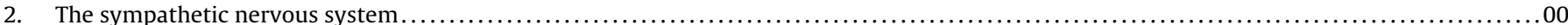

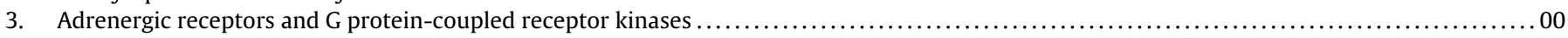

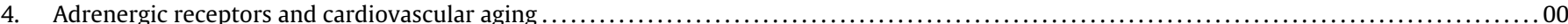

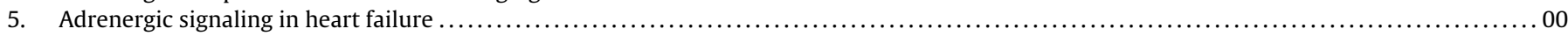

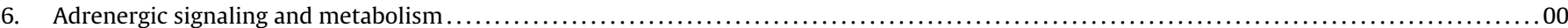

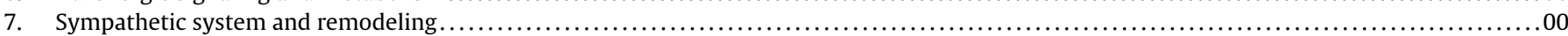

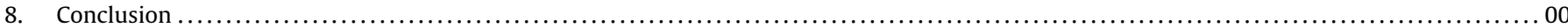

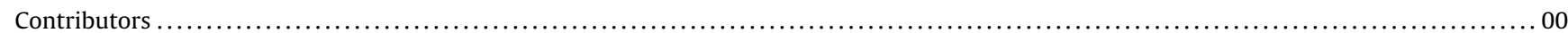

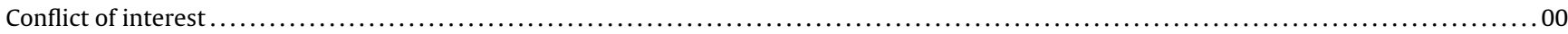

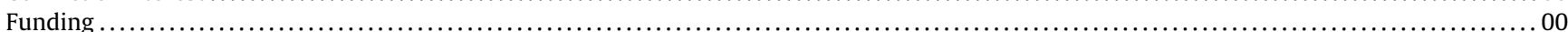

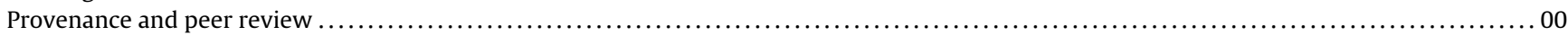

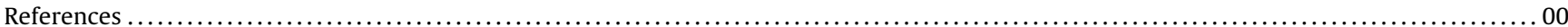

\section{Introduction}

Aging is associated with a progressive decline in physiological processes. Cardiovascular disease, and heart failure in particular, remains the leading cause of death among the elderly [1]. Therefore, it is indispensable to explore the molecular mechanisms underlying age-related cardiovascular disorders.

\footnotetext{
* Corresponding authors.

E-mail addresses: gs2620@cumc.columbia.edu, gsantulli001@gmail.com (G. Santulli),giaccarino@unisa.it (G. Iaccarino).
}

Many of the physiological paradigms developed during the last decades of research in the biological and medical fields may reveal inadequate to understand the aging pathophysiology, in which adaptive and maladaptive mechanisms combine in a new and delicate equilibrium, a thin red line that divides the healthy aging from the fragile individual. The sympathetic nervous system is one of such mechanisms that with aging undergo a series of rearrangements, from baroreflex sensitivity to adrenergic signaling. Over the course of the years the sympathetic nervous system changes its ability to regulate many physiological functions including, not exclusively, the cardiovascular system. 


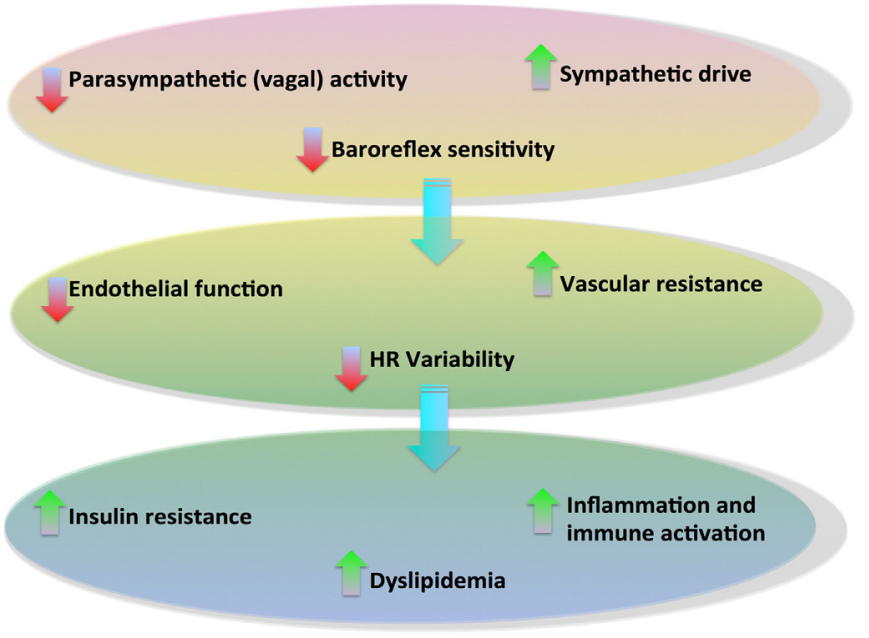

Fig. 1. Common features in cardiovascular aging and heart failure.

Cardiac aging is characterized by several complex modifications including diastolic dysfunction, left ventricular hypertrophy, increased risk of atrial fibrillation, valvular degeneration, leading to a decreased maximal exercise capacity. Intriguingly, the sympathetic nervous system plays a key role in both aging and cardiovascular disease. Indeed, adrenergic receptors (ARs) are involved in a variety of pathophysiological processes and mounting evidence indicates their participation in aging and cardiovascular physiopathology (Fig. 1).

\section{The sympathetic nervous system}

The aging process is accompanied by a series of changes in the autonomic control of the cardiovascular system, favoring heightened cardiac sympathetic tone with parasympathetic withdrawal and blunted cardiovagal baroreflex sensitivity. In a study of older males, the peripheral plasma norepinephrine concentration was approximately $66 \%$ higher than that observed in younger men. This finding is explained by the reduction in the rate of clearance of norepinephrine from plasma and $29 \%$ higher whole-body norepinephrine spillover to plasma The cardiac spillover of catecholamines is higher in older than in younger men [2,3]. Different factors can play a role in determining the rate of spillover of norepinephrine from sympathetic nerve terminals to plasma including nerve traffic, pre-junctional modulation, and the rate of catecholamine reuptake, principally via neuronal uptake.

\section{Adrenergic receptors and $G$ protein-coupled receptor kinases}

Adrenergic receptors (ARs) belong to the guanine nucleotidebinding $G$ protein-coupled receptor (GPCR) superfamily, and are membrane receptors that activate heterotrimeric $G$ proteins. GPCRs consist of one extracellular N-terminal domain, seven membranespanning domains, three intra- and three extracellular loops, and one intracellular $C$-terminal tail. $G$ proteins typically stimulate $\left(G_{s}\right.$ protein) or inhibit ( $G_{i}$ protein) the enzyme adenylyl-cyclase, or activate $\left(G_{q}\right.$ protein) phospholipase C (PLC). GPCR signaling is stopped by the family of $G$ protein-coupled receptor kinases (GRKs). GRKmediated phosphorylation leads to an increased affinity of GPCRs for the arrestin class of proteins, which then uncouples the phosphorylated receptor from $G$ protein and targets the receptor for internalization [4].

Two classes of ARs have been identified: $\alpha$ and $\beta$. Phenylephrine is a selective agonist of $\alpha \mathrm{AR}$ while isoproterenol is a non-selective agonist for $\beta$ AR [5]. The subfamily of $\alpha_{1} A R\left(G_{q}\right.$ coupled receptors) consists of three highly homologous subtypes, including $\alpha_{1} A-, \alpha_{1} B-$ and $\alpha_{1}$ D-AR [6]. The $\alpha_{2}$ AR subfamily (coupled to $G_{i}$ ) comprises three subtypes: $\alpha_{2} A-, \alpha_{2} B$ - and $\alpha_{2} C$-AR [7]. Some species express a fourth $\alpha_{2}$ D-AR [8]. In the $\beta A R$ family there are three receptor subtypes: $\beta_{1}$ AR is highly expressed in the heart [9], $\beta_{2}$ AR is widely distributed throughout the body [10], and $\beta_{3} A R$ is found, although not exclusively, in the white and brown adipose tissue [11]. All $\beta A R s$ couple primarily to $G \alpha_{s}$ and subsequent cAMP-related pathways, however under certain conditions they can couple to $\mathrm{G} \alpha_{\mathrm{i}}$ [12].

Notably, $\beta_{2}$ AR and $\beta_{3}$ AR signaling can also occur via mechanisms independent from $G$ protein [13]. Additionally, the response to GPCR stimulus can be modified by various parameters, including chronic stimulation, cell hypoxia, acidosis, and aging [14-16].

GRKs have a significant role in the regulation of adrenergic responses. Generally, GRK2 is considered the most important isoform of the 7 mammalian GRKs. Indeed mice with homozygous deletion of GRK2 exhibit embryonic lethality whereas gene ablation for the other GRKs resulted in relatively mild phenotypes [17-19]. GRK-mediated desensitization does not rely only on its catalytic activity but also on protein-protein interactions occurring in different cellular compartments [20]. Both up-regulated and reduced levels of GRK2 may affect cellular functioning. Alterations in GRK2 activity and expression have been described in numerous diseases, including myocardial infarction [21], Alzheimer's disease [22], rheumatoid arthritis [23], multiple sclerosis [24], inflammatory pain [25,26], opioid addiction [26], thyroid gland disorders [27], pituitary adenomas [28], ovarian cancer [29], and cystic fibrosis [30].

GRK2 levels in peripheral blood lymphocytes have been reported to mirror changes in kinase expression in other organs under several pathophysiological settings [21]. In particular, GRK2 levels and activity are increased in lymphocytes from hypertensive patients. Impairment of $\beta$-adrenergic mediated vasodilation has been reported in both human hypertensive subjects and animal models of hypertension, and such an alteration has been related to the increased GRK2 abundance and activity [31]. Decreased $\beta$ adrenergic signaling due to increased GRK2 activity would reduce the vasodilatative response, leading to high blood pressure. This view is supported by the inverse correlation of GRK2 expression with blood pressure. Additionally, data from spontaneously hypertensive rats and Dahl salt-sensitive rats confirm increased levels of GRK2 in vascular smooth muscle cells, consistent with the observations in peripheral lymphocytes [32].

As discussed below in the section dedicated to adrenergic signaling and metabolism, elevated GRK2 levels could imply metabolic alterations and lead to insulin-resistance [13,33,34].

To summarize, control of endothelium homeostasis relies on a complex interaction between adrenergic system and nitroxidative stress, where specific molecules as GRKs may interplay with and modulate their crosstalk.

\section{Adrenergic receptors and cardiovascular aging}

The age-associated decrease in catecholamine-responsiveness in the elderly is well established. In particular, an age-related reduction in $\beta A R$ sensitivity and density has been shown in the myocardium and has been attributed to down-regulation and impaired coupling of $\beta$ ARs to adenylyl-cyclase $\{$ Xiao, 1998 $\# 1544\}$. The age-linked decline in cardiac $\beta A R$ response appears to be due to a down-regulation of $\beta_{1} A R s$, as reported in experiments in aged explanted human hearts [35]. Additionally, a decreased sensitivity of $\beta$ ARs, measured by isoproterenol-induced changes in the catecholamine-stimulated adenylyl-cyclase activity has been shown in the cardiovascular system [10]. BARs 
compartmentalization may also participate in the age-associated decreased $\beta A R$ responsiveness [36]. Indeed, whereas $\beta_{1}$ ARs are widely distributed on the plasma membrane, $\beta_{2}$ ARs are usually located in the transverse tubules, containing specialized proteins that couple membrane depolarization (excitation) to calcium-mediated myofilament shortening (contraction) [10,37-39]. Henceforward, the localization of $\beta_{2} A R$ in cardiac cells leads to the generation of spatially restricted cAMP production, affecting calcium-dependent proteins that control the contraction of myofilaments [40,41]. Several conditions presenting a decreased myocardial function can elicit activity from the sympathetic nervous system (SNS) that eventually diverts blood flow to critical organs and increases cardiac output. The main players involved in such system are catecholamines, whose release is strictly orchestrated by the GPCR system, relating the adrenal gland and the heart [42].

Most of the modifications in the sympathetic nervous system occurring with aging, including decreased $\beta A R$ responsiveness, increased circulating catecholamines, and overall hyposensitivity to adrenergic stress, are also observed in patients with failing hearts. Moreover, young people are more reactive to isoproterenolinduced increase in blood flow than elderly subjects [31].

Vascular tone is finely regulated by the intimal (endothelial cells, EC) and the medial (vascular smooth muscle cells, VSMC) layers [43-45] and both EC and VSMC express $\beta_{2}$ AR [46-48]. The age-related decline in $\beta_{2}$ AR function and successive cAMP generation is observed in diverse cardiovascular disorders, including atherosclerosis, hypertension, vascular insufficiency, and orthostatic hypotension, all conditions with significant mortality and morbidity [49-53]. The increased incidence of restenosis and atherosclerosis in aged people may also rely on the age-associated deterioration in $\beta A R$-mediated cAMP production, since cAMP may inhibit VSMC proliferation [45,54]. A reduced responsiveness with age has been also reported for $\alpha$ AR in healthy subjects [55], with potential implications for reduced muscle blood flow and augmented blood pressure during exercise [56-58].

During the late 90's the idea that the EC possessed functional BARs became more and more evident, and soon this system was seen as a therapeutic target $[59,60]$. Nevertheless, the proangiogenic effects of the $\beta_{2}$ AR was firstly identified by our group in 2005 [47]. The picture was completed, when we finally demonstrated that the endothelium is the source of catecholamines that stimulate in a paracrine manner endothelial $\beta$ ARs [46]. These findings were further corroborated by the observation that also endothelial progenitor cells express $\beta_{2} \mathrm{AR}$ and that the ability of this receptor to signaling to eNOS promotes angiogenesis through multiple mechanisms [61]. This ability is lost during aging. Strategies that aim to restore $\beta_{2}$ AR signaling in models where it is lost are effective to restore also impaired angiogenesis $[47,62]$. For instance, in aging the enhancement of $\beta A R$ signaling leads to the correction of impaired angiogenesis $[10,63,64]$.

The overall incidence of cardiac disorders including heart failure, left ventricular hypertrophy, and arrhythmias, increases considerably with age $[1,65]$. Elderly people appear to be particularly predisposed to the development of heart failure: such a diagnosis is the leading cause of hospitalizations in people $>65$ years of age $[1,15]$. Additionally, alterations in ventricular relaxation and filling have been described with aging $[64,66]$.

The prevalence of atrial fibrillation reaches values of $17.8 \%$ in people $>85$ years $[1,67,68]$. The development of a non-regular pattern of electrical activity might have detrimental consequences in hearts that are relatively stiff and relax slowly $[1,69,70]$.

Likewise, the prevalence of left ventricular hypertrophy increases with rising blood pressure and body mass index [71,72] and studies in normotensive people indicate that myocardial wall thickness increases progressively with age [73].
In the vasculature an age-linked increase in intimal thickening has been reported, accompanied by luminal dilatation and reduction in distensibility, resulting in increased vessel stiffness. Indeed, pulse wave velocity, a noninvasive index of vascular stiffening, increases with age and has been associated with structural alterations in the media $[13,44,48,49,64,74-76]$.

\section{Adrenergic signaling in heart failure}

The SNS has prominent effects on cardiac physiology, including increases in atrioventricular conduction (positive dromotropy), heart rate (positive chronotropy), cardiac contractility (positive inotropy), and cardiac relaxation (positive lusitropy). Crucially, the SNS plays a crucial role in the regulation of vascular tone by controlling both peripheral resistance and cardiac output $[77,78]$.

Heart failure is a chronic syndrome in which the heart is unable of pumping an adequate supply of blood to meet the metabolic requirements of the body or generating the required elevated ventricular filling pressures to maintain output [34]. Despite considerable advances in the treatment of heart failure, such a disease still represents a severe social and clinical burden $[42,79,80]$. The cardiovascular system is best viewed as a complex dynamic system, continually adapting to optimize organ perfusion. During heart failure, diverse neurohormonal mechanisms are triggered to maintain cardiac output [4]. Heart failure is considered a progressive disease that begins long before signs or symptoms become clinically evident: initially there is a complex adaptive neurohormonal activation - required to compensate for cardiac dysfunction - which includes nervous system, renin-angiotensin-aldosterone system, endothelin, natriuretic peptides, and vasopressin. The process progressively becomes maladaptive, leading to increased mechanical stress on the failing heart and causing harmful electrical and structural events [81-83]. Thus, $\beta$-blockers, Angiotensin II $\mathrm{AT}_{1}$ receptor blockers, angiotensin-converting enzyme inhibitors, and mineralocorticoid receptor antagonists represent cornerstones for the treatment of patients with heart failure. Given the decreased myocardial contractility observed in heart failure and the positive inotropic response obtained with $\beta A R$ agonists, it was initially attractive to attempt to overcome the $\beta A R$ desensitization in order to ameliorate cardiac function via the stimulation of the adrenergic system [84]. Several authors also provided experimental evidence that $\beta_{2}$ AR overexpression might have been a new treatment for heart failure $[85,86]$. Other investigators demonstrated that the overexpression of $\beta_{1} A R$ [87] or $\beta_{2} A R$ [88] leads to cardiomyopathy and heart failure, as reflected by decreased cardiac function, increased fibrosis, cardiomyocyte apoptosis, and overall mortality.

The central part of the adrenal gland, called adrenal medulla, is the main source of catecholamines and is comprised of groups of adrenergic and noradrenergic chromaffin cells and, to a lesser extent, ganglionic neurons $[42,89]$. The adrenal gland can be seen as a specialized sympathetic ganglion, receiving inputs from the sympathetic nervous system via pre-ganglionic fibers. Yet, the adrenal gland directly secretes neurohormones into the bloodstream [89].

The sympathetic overdrive observed in heart failure correlates with a higher risk of arrhythmias and left ventricular dysfunction [90]. Moreover, augmented levels of catecholamines can cause myocardial damage via enhanced cardiac oxygen demand and by increasing peroxidative metabolism [91] and ultimately leading to structural alterations, including focal necrosis and inflammation, increased collagen deposition, and interstitial fibrosis [92-94].

Systemically circulating or locally released catecholamines trigger two main classes of ARs: $\alpha_{1}$ AR and $\beta_{2}$ AR, causing vasoconstriction and vasodilatation, respectively $[46,47,95]$. With aging, such a fine equilibrium is progressively shifted toward increased 
vasoconstriction, most likely due to a defective vasodilatation in response to $\beta A R$ stimulation.

Increased basal levels of circulating catecholamines have been observed both in heart failure and with advancing age, mirrored by a decrease in the number of high-affinity $\beta$ ARs. These findings suggest that these alterations might be attributable to $\beta$ AR desensitization rather than an actual reduction in $\beta$ AR density $[10,21,96]$.

Both expression and activity of GRK2 increase in vascular tissue with aging [97]. Equally important, an impairment in BAR-mediated vasorelaxation has been observed in hypertensive patients [31] and in animal models of hypertension [75,97]: such an alteration has been related to increased GRK2 abundance and activity. Transgenic overexpression of GRK2 in the vasculature impairs $\beta A R$ signaling and the vasodilatative response, eliciting a hypertensive phenotype in rodents. This aspect has been confirmed in humans: GRK2 expression correlates with blood pressure and impaired $\beta A R-$ mediated adenylyl-cyclase activity [97]. Additionally, variants of the gene encoding for $\beta_{2}$ AR have been associated with longevity [10].

The decreased $\beta$ AR-mediated response has been attributed to different mechanisms, including an attenuation of PKA activation, an impaired generation of cyclic AMP, a reduced receptor density, and a less efficient coupling to adenylyl-cyclase [10]. However, currently there is no single molecular or cellular factor that can fully explain the decline in $\beta$ AR function. Nonetheless, the etiology seems to be most likely associated with alterations in the ability of $\beta A R$ to respond to agonists at the cellular level.

\section{Adrenergic signaling and metabolism}

The adrenergic system is involved in regulating several metabolic pathways. Increased circulating catecholamines and activation of the different ARs present in the various organs produce important metabolic responses, including increased gluconeogenesis by the liver to provide substrate for the brain, increased lipolysis and elevated levels of fatty acids in plasma, and modulation of insulin secretion by pancreatic islets of Langerhans. Such responses are detrimental to the functioning of different organs (e.g. the heart). Metabolic modifications including insulin resistance, altered glucose and lipid metabolism, and mitochondrial dysfunction represent common features of many conditions involving adrenergic overdrive. Notably, these alterations are seen in a number of different pathological conditions and are generally highly correlated with the level of activation of the sympathetic system.

Chronic $\beta A R$ stimulation induces insulin resistance and in this context the $\beta_{2}$ AR has a key role in overall glucose homeostasis by modulating pancreatic islet hormone secretion as well as liver and muscle glucose homeostasis. Short- and long-term stimulation of the $\beta_{2} A R$ has been associated with the modulation of fatty acid and glucose metabolism [98]. Indeed, acute treatment with $\beta_{2} \mathrm{AR}$ agonists of myocytes or skeletal muscle increases glucose uptake to levels comparable to those seen after insulin stimulation [99].

A potential mechanism for $\beta_{2}$ AR function in insulin resistance involves the activation of PI3K and its downstream signal pathway and in particular the phosphorylation and inactivation of TBC1D4 by AKT [100]. TBC1D4 inhibits the translocation to the plasma membrane of the glucose transporter type 4 (GLUT4) [100]. Moreover, TBC1D4 is also targeted by AMPK, which represents a pivotal mechanism in the regulation of insulin-independent glucose uptake $[100,101]$. Strikingly, higher levels of AMPK phosphorylation and activity are seen in response to $\beta A R$ stimulation $[102,103]$ as a result of changes in the AMP/ATP ratio or activation of upstream AMPK kinases [104]. Besides, in vivo studies show a greater efficiency of carvedilol, a non-selective $\beta A R$ antagonist, in ameliorating myocardial insulin sensitivity and glucose extraction in an animal model of heart failure, compared to the selective $\beta_{1}$ AR antagonist metoprolol [105]. Chronic adrenergic stimulation, as seen during heart failure, would be detrimental by mechanisms involving mechanisms such as JNK, $\beta$-arrestins and GRKs $[4,106]$.

Insulin resistance highly correlates with adrenergic function [75,107-111]. In both type 2 diabetes mellitus (T2DM) and heart failure circulating insulin levels are elevated, causing a persistent stimulation of insulin receptors [52,112-117]. Hyperactive insulin signaling can accelerate adverse left ventricular remodeling $[72,118]$. Recently, insulin has been demonstrated to directly impair adrenergic pathways for contractile function via an insulin receptor $/ \beta_{2} A R$ signaling complex [114].

In numerous conditions associated with insulin resistance, such as hypertension and T2DM, there are elevated GRK2 levels [97,119]. In vitro experiments demonstrated that insulin increases GRK2 levels, causing GRK2-IRS1 association [97,120]. On these bases, GRK2 inhibition has been proposed to be beneficial. Indeed, chronic treatment of spontaneously hypertensive rats with an inhibitor of GRK2 kinase activity ameliorates glucose homeostasis and decreases blood pressure [120].

Growing evidence indicates that GRKs can exert different effects within the cell depending on the stimulus, cell type, and localization $[97,121]$. In this sense, we were the first to demonstrate a mitochondrial localization for GRK2 [122], later confirmed by other investigators [123], establishing a functional role for GRK2 in organelle biogenesis and ATP production [122,124].

\section{Sympathetic system and remodeling}

Histopathologic evaluation in murine hearts reveals subendocardial and interstitial fibrosis, vacuolization of cytoplasm and mineralization [16,125-127]. Furthermore, morphometric analysis of cardiomyocytes demonstrates a progressive hypertrophy, increased apoptosis alongside with fibrosis and amyloid deposition [128].

Several organs undergo fibrotic remodeling as a function of age resulting in overall decreased functionality. The precise mechanisms leading to the age-dependent accumulation of collagen have yet to be fully identified. Mounting evidence reveals the emerging role of collagen cross-linkers and matrix metalloproteinases (MMP) in the turnover of collagens, finely regulated by proteolytic MMP activity and their endogenous tissue inhibitors (TIMPs) $[129,130]$. All of these mechanisms are modulated by neuroendocrine activation and $\beta A R$ signal transduction modifications. Indeed, chronic sympathetic activation significantly contributes to progression from compensated left ventricular hypertrophy to myocardial dysfunction through detrimental cardiac matrix remodeling. Besides, sympathetic overactivity achieved via $\beta_{1}$ AR overexpression ( $\beta_{1}$ TG mouse) $[87,131]$ is accompanied by interstitial matrix remodeling and turnover by inducing MMP/TIMPs. In $\beta_{1}$ TG pro-collagen typeI and type-III mRNA and interstitial collagen protein expression are progressively increased from four-fold at 5 months to 17 -fold at 12 months compared to 3 months of age. In $\beta_{1}$ TG mice at 5 months of age with compensated cardiac hypertrophy, an increased deposition of type-I and -III collagen fibers surrounding the cardiomyocytes is observed [131]. Contrariwise, the $\beta_{1}$ TG group at 12 months of age exhibits an asymmetrical distribution of the collagen fibers with disruption of the collagen network structure $[132,133]$.

A positive correlation between MMP-2 and noradrenaline in patients with heart failure has been demonstrated, also corroborated by in vitro experiments in human cardiac fibroblasts [134], supporting thereby the link between sympathetic stimulation and collagen turnover. 


\section{Conclusion}

With aging the sympathetic nervous system undergoes a series of rearrangements, from baroreflex sensitivity to adrenergic signaling, and over the course of the years, it changes its ability to regulate countless physiological functions. The exaggerated sympathetic activity observed in aging, discussed in this report, has to be put into the perspective of a whole scenario, in which the effectors of catecholamines are also undergoing a plasticity with the ultimate intent of allowing an adequate signaling.

\section{Contributors}

Both authors contributed significantly to the work, read the manuscript, and agreed to its submission.

\section{Conflict of interest}

None declared.

\section{Funding}

Dr. Gaetano Santulli, MD, PhD is supported by the National Institutes of Health (K99DK107895).

\section{Provenance and peer review}

This article has undergone peer review.

\section{References}

[1] G. Santulli, Epidemiology of cardiovascular disease in the 21st century: updated numbers and updated facts, J. Cardiovasc. Dis. 1 (1) (2013) 1-2

[2] M. Esler, G. Lambert, D. Kaye, M. Rumantir, J. Hastings, D.R. Seals, Influence of ageing on the sympathetic nervous system and adrenal medulla at rest and during stress, Biogerontology 3 (1-2) (2002) 45-49.

[3] D. Kaye, M. Esler, Sympathetic neuronal regulation of the heart in aging and heart failure, Cardiovasc. Res. 66 (2) (2005) 256-264

[4] R. Hatton, A. Cvjeticanin, A. Lymperopoulos, The adrenergic system of the adrenal glands as a remote control of cardiac function, J. Cardiovasc. Dis. 5 (3) (2015) 394-397.

[5] Y. Mei, N. Yin, X. Jin, J. He, Z. Yin, The regulatory role of the adrenergic agonists phenylephrine and isoproterenol on fetal hemoglobin expression and erythroid differentiation, Endocrinology 154 (12) (2013) 4640-4649.

[6] E. Lampri, E. Ioachim, Angiogenesis: something old, something new, in: Gaetano Santulli (Ed.), Angiogenesis: Insight from a Systematic Overview, Nova Science Publishers, 2013, pp. 1--30.

[7] T.D. O'Connell, B.C. Jensen, A.J. Baker, P.C. Simpson, Cardiac alpha1-adrenergic receptors: novel aspects of expression, signaling mechanisms, physiologic function, and clinical importance, Pharmacol. Rev. 66 (1) (2014) 308-333.

[8] J.O. Ruuskanen, J. Laurila, H. Xhaard, V.V. Rantanen, K. Vuoriluoto, S. Wurster, A. Marjamaki, M. Vainio, M.S. Johnson, M. Scheinin, Conserved structural, pharmacological and functional properties among the three human and five zebrafish alpha 2-adrenoceptors, Br. J. Pharmacol. 144 (2) (2005) 165-177.

[9] M.H. Vicco, N. Pujato, I. Bontempi, L. Rodeles, I. Marcipar, O.A. Bottasso, Beta1-selective adrenoceptor antagonists increase plasma levels of anti-p2beta antibodies and decrease cardiac involvement in chronic progressive chagas heart disease, Can. J. Cardiol. 30 (3) (2014) 332-337.

[10] G. Santulli, G. Iaccarino, Pinpointing beta adrenergic receptor in ageing pathophysiology: victim or executioner? Evidence from crime scenes, Immun. Ageing 10 (1) (2013) 10.

[11] C. Belge, J. Hammond, E. Dubois-Deruy, B. Manoury, J. Hamelet, C. Beauloye, A. Markl, A.C. Pouleur, L. Bertrand, H. Esfahani, K. Jnaoui, K.R. Gotz, V.O. Nikolaev, A. Vanderper, P. Herijgers, I. Lobysheva, G. Iaccarino, D. Hilfiker-Kleiner, G. Tavernier, D. Langin, C. Dessy, J.L. Balligand, Enhanced expression of beta3-adrenoceptors in cardiac myocytes attenuates neurohormone-induced hypertrophic remodeling through nitric oxide synthase, Circulation 129 (4) (2014) 451-462.

[12] R.P. Xiao, Beta-adrenergic signaling in the heart: dual coupling of the beta2-adrenergic receptor to G(s) and G(i) proteins, Sci. STKE 2001 (104) (2001) re15.

[13] G. Santulli, A. Lombardi, D. Sorriento, A. Anastasio, C. Del Giudice, P. Formisano, F. Beguinot, B. Trimarco, C. Miele, G. Iaccarino, Age-related impairment in insulin release: the essential role of beta(2)-adrenergic receptor, Diabetes 61 (3) (2012) 692-701.
[14] A.I. Kaya, H.O. Onaran, G. Ozcan, C. Ambrosio, T. Costa, S. Balli, O. Ugur, Cell contact-dependent functional selectivity of beta2-adrenergic receptor ligands in stimulating cAMP accumulation and extracellular signal-regulated kinase phosphorylation, J. Biol. Chem. 287 (9) (2012) 6362-6374.

[15] G. Santulli, A.R. Marks, Essential roles of intracellular calcium release channels in muscle, brain, metabolism, and aging, Curr. Mol. Pharmacol. 8 (2) (2015) 206-222

[16] Q. Yuan, Z. Chen, G. Santulli, L. Gu, Z.G. Yang, Z.Q. Yuan, Y.T. Zhao, H.B. Xin, K.Y. Deng, S.Q. Wang, G. Ji, Functional role of calstabin2 in age-related cardiac alterations, Sci. Rep. 4 (2014) 7425.

[17] R.R. Gainetdinov, L.M. Bohn, T.D. Sotnikova, M. Cyr, A. Laakso, A.D. Macrae, G.E. Torres, K.M. Kim, R.J. Lefkowitz, M.G. Caron, R.T. Premont, Dopaminergic supersensitivity in G protein-coupled receptor kinase 6-deficient mice, Neuron 38 (2) (2003) 291-303.

[18] A.L. Lyubarsky, C. Chen, M.I. Simon, E.N. Pugh Jr., Mice lacking G-protein receptor kinase 1 have profoundly slowed recovery of cone-driven retinal responses, J. Neurosci. 0 (6) (2000) 2209-2217.

[19] J.K. Walker, R.R. Gainetdinov, D.S. Feldman, P.K. McFawn, M.G. Caron, R.J Lefkowitz, R.T. Premont, J.T. Fisher, G protein-coupled receptor kinase 5 regulates airway responses induced by muscarinic receptor activation, Am. J. Physiol. Lung Cell. Mol. Physiol. 286 (2) (2004) L312-L319.

[20] A. Fusco, G. Santulli, D. Sorriento, E. Cipolletta, C. Garbi, G.W. Dorn 2nd, B. Trimarco, A. Feliciello, G. Iaccarino, Mitochondrial localization unveils a novel role for GRK2 in organelle biogenesis, Cell. Signal. 24 (2) (2011) $468-475$.

[21] G. Santulli, A. Campanile, L. Spinelli, E. Assante di Panzillo, M. Ciccarelli, B. Trimarco, G. Iaccarino, G protein-coupled receptor kinase 2 in patients with acute myocardial infarction, Am. J. Cardiol. 107 (8) (2011) 1125-1130.

[22] Z. Suo, M. Wu, B.A. Citron, G.T. Wong, B.W. Festoff, Abnormality of G-protein-coupled receptor kinases at prodromal and early stages of Alzheimer's disease: an association with early beta-amyloid accumulation, J. Neurosci. 24 (13) (2004) 3444-3452.

[23] M.S. Lombardi, A. Kavelaars, M. Schedlowski, J.W. Bijlsma, K.L. Okihara, M. Van de Pol, S. Ochsmann, C. Pawlak, R.E. Schmidt, C.J. Heijnen, Decreased expression and activity of G-protein-coupled receptor kinases in peripheral blood mononuclear cells of patients with rheumatoid arthritis, FASEB J. 13 (6) (1999) 715-725

[24] A. Vroon, A. Kavelaars, V. Limmroth, M.S. Lombardi, M.U. Goebel, A.M. Van Dam, M.G. Caron, M. Schedlowski, C.J. Heijnen, G protein-coupled receptor kinase 2 in multiple sclerosis and experimental autoimmune encephalomyelitis, J. Immunol. 174 (7) (2005) 4400-4406.

[25] P. Singhmar, X. Huo, N. Eijkelkamp, S.R. Berciano, F. Baameur, F.C. Mei, Y. Zhu, X. Cheng, D. Hawke, F. Mayor Jr., C. Murga, C.J. Heijnen, A. Kavelaars, Critical role for Epac1 in inflammatory pain controlled by GRK2-mediated phosphorylation of Epac1, Proc. Natl. Acad. Sci. U.S.A. (2016), in press.

[26] J. Zhang, S.S. Ferguson, P.Y. Law, L.S. Barak, M.G. Caron, Agonist-specific regulation of delta-opioid receptor trafficking by $\mathrm{G}$ protein-coupled receptor kinase and beta-arrestin, J. Recept. Signal Transduct. Res. 19 (1-4) (1999) 301-313.

[27] T. Metaye, E. Menet, J. Guilhot, J.L. Kraimps, Expression and activity of g protein-coupled receptor kinases in differentiated thyroid carcinoma, J. Clin. Endocrinol. Metab. 87 (7) (2002) 3279-3286.

[28] F. Gatto, R. Feelders, R. van der Pas, J.M. Kros, F. Dogan, P.M. van Koetsveld, A.J. van der Lelij, S.J. Neggers, F. Minuto, W. de Herder, S.W. Lamberts, D. Ferone, L.J. Hofland, beta-Arrestin 1 and 2 and $G$ protein-coupled receptor kinase 2 expression in pituitary adenomas: role in the regulation of response to somatostatin analogue treatment in patients with acromegaly, Endocrinology 154 (12) (2013) 4715-4725.

[29] D.W. King, R. Steinmetz, H.A. Wagoner, T.S. Hannon, L.Y. Chen, E.A. Eugster O.H. Pescovitz, Differential expression of GRK isoforms in nonmalignant and malignant human granulosa cells, Endocrine 22 (2) (2003) 135-142.

[30] J. Roux, C.M. McNicholas, M. Carles, A. Goolaerts, B.T. Houseman, D.A Dickinson, K.E. Iles, L.B. Ware, M.A. Matthay, J.F. Pittet, IL-8 inhibits cAMP-stimulated alveolar epithelial fluid transport via a GRK2/PI3K-dependent mechanism, FASEB J. 27 (3) (2013) 1095-1106.

[31] R. Izzo, E. Cipolletta, M. Ciccarelli, A. Campanile, G. Santulli, G. Palumbo, A. Vasta, S. Formisano, B. Trimarco, G. Iaccarino, Enhanced GRK2 expression and desensitization of betaAR vasodilatation in hypertensive patients, Clin. Transl. Sci. 1 (3) (2008) 215-220.

[32] R. Gros, J. Chorazyczewski, M.D. Meek, J.L. Benovic, S.S. Ferguson, R.D. Feldman, G-Protein-coupled receptor kinase activity in hypertension: increased vascular and lymphocyte G-protein receptor kinase-2 protein expression, Hypertension 35 (1 Pt 1) (2000) 38-42.

[33] M.P. De Boer, R.I. Meijer, N.J. Wijnstok, A.M. Jonk, A.J. Houben, C.D. Stehouwer, Y.M. Smulders, E.C. Eringa, E.H. Serne, Microvascular dysfunction: a potential mechanism in the pathogenesis of obesity-associated insulin resistance and hypertension, Microcirculation 19 (1) (2012) 5-18.

[34] G. Santulli, The adrenergic system in cardiovascular metabolism and aging, in: A. Lymperopoulos (Ed.), The Cardiovascular Adrenergic System, Springer, 2015, pp. 97-116.

[35] M. White, R. Roden, W. Minobe, M.F. Khan, P. Larrabee, M. Wollmering, J.D. Port, F. Anderson, D. Campbell, A.M. Feldman, et al., Age-related changes in beta-adrenergic neuroeffector systems in the human heart, Circulation 90 (3) (1994) 1225-1238. 
[36] E.S. Nakou, F.I. Parthenakis, E.M. Kallergis, M.E. Marketou, K.S. Nakos, P.E Vardas, Healthy aging and myocardium: a complicated process with various effects in cardiac structure and physiology, Int. J. Cardiol. 209 (2016) $167-175$.

[37] W. Xie, G. Santulli, X. Guo, M. Gao, B.X. Chen, A.R. Marks, Imaging atrial arrhythmic intracellular calcium in intact heart, J. Mol. Cell. Cardiol. 64 (2013) 120-123.

[38] A. Umanskaya, G. Santulli, W. Xie, D.C. Andersson, S.R. Reiken, A.R. Marks, Genetically enhancing mitochondrial antioxidant activity improves muscle function in aging, Proc. Natl. Acad. Sci. U.S.A. 111 (42) (2014) 15250-15255.

[39] G. Santulli, W. Xie, S.R. Reiken, A.R. Marks, Mitochondrial calcium overload is a key determinant in heart failure, Proc. Natl. Acad. Sci. U.S.A. 112 (36) (2015) 11389

[40] J.A. Kirk, R.J. Holewinski, V. Kooij, G. Agnetti, R.S. Tunin, N. Witayavanitkul, P.P. de Tombe, W.D. Gao, J. Van Eyk, D.A. Kass, Cardiac resynchronization sensitizes the sarcomere to calcium by reactivating GSK-3beta, J. Clin. Invest. 124 (1) (2014) 129-138.

[41] P.T. Wright, V.O. Nikolaev, T. O'Hara, I. Diakonov, A. Bhargava, S. Tokar, S. Schobesberger, A.I. Shevchuk, M.B. Sikkel, R. Wilkinson, N.A. Trayanova, A.R. Lyon, S.E. Harding, J. Gorelik, Caveolin-3 regulates compartmentation of cardiomyocyte beta2-adrenergic receptor-mediated cAMP signaling, J. Mol. Cell. Cardiol. 67 (2014) 38-48

[42] G. Santulli, Adrenal signaling in heart failure: something more than a distant ship's smoke on the horizon, Hypertension 63 (2) (2014) 215-216.

[43] G. Santulli, M.F. Basilicata, M. De Simone, C. Del Giudice, A. Anastasio, D. Sorriento, M. Saviano, A. Del Gatto, B. Trimarco, C. Pedone, L. Zaccaro, G Iaccarino, Evaluation of the anti-angiogenic properties of the new selective alphaVbeta3 integrin antagonist RGDechiHCit, J. Transl. Med. 9 (2011) 7.

[44] G. Santulli, A. Wronska, U. Kunihiro, T. Diacovo, M. Gao, S. Marx, J. Kitajewski, J. Chilton, M. Kemal, T. Tuschl, A.R. Marks, H. Totary Jain, A selective microRNA-based strategy inhibits restenosis while preserving endothelial function, J. Clin. Invest. 124 (2014) 4102-4114.

[45] G. Santulli, microRNAs distinctively regulate vascular smooth muscle and endothelial cells: functional implications in angiogenesis, atherosclerosis and in-stent restenosis, Adv. Exp. Med. Biol. 887 (2015) 53-77.

[46] D. Sorriento, G. Santulli, C. Del Giudice, A. Anastasio, B. Trimarco, G. Iaccarino, Endothelial cells are able to synthesize and release catecholamines both in vitro and in vivo, Hypertension 60 (1) (2012) 129-136.

[47] G. Iaccarino, M. Ciccarelli, D. Sorriento, G. Galasso, A. Campanile, G. Santulli, E. Cipolletta, V. Cerullo, V. Cimini, G.G. Altobelli, F. Piscione, O. Priante, L. Pastore, M. Chiariello, F. Salvatore, W.J. Koch, B. Trimarco, Ischemic neoangiogenesis enhanced by beta2-adrenergic receptor overexpression: novel role for the endothelial adrenergic system, Circ. Res. 97 (11) (2005) $1182-1189$

[48] G. Santulli, microRNAs and endothelial (Dys) function, J. Cell. Physiol. (2015), in press

[49] G. Santulli, E. Cipolletta, D. Sorriento, C. Del Giudice, A. Anastasio, S. Monaco, A.S. Maione, G. Condorelli, A. Puca, B. Trimarco, M. Illario, G. Iaccarino, CaMK4 gene deletion induces hypertension, J. Am. Heart Assoc. 1 (4) (2012) e001081.

[50] G. Santulli, Coronary heart disease risk factors and mortality, JAMA 307 (11) (2012) 1137.

[51] T.H. Vu, J. Stamler, K. Liu, M.M. McDermott, D.M. Lloyd-Jones, A. Pirzada, D.B. Garside, M.L. Daviglus, Prospective relationship of low cardiovascular risk factor profile at younger ages to ankle-brachial index: 39-year follow-up-the chicago healthy aging study, J. Am. Heart Assoc. 1 (6) (2012) e001545.

[52] C. Sardu, R. Marfella, G. Santulli, Impact of diabetes mellitus on the clinical response to cardiac resynchronization therapy in elderly people, J. Cardiovasc. Trans. Res. 7 (3) (2014) 362-368.

[53] M. Ciccarelli, R. Finelli, N. Rivera, G. Santulli, R. Izzo, N. De Luca, F. Rozza, M Ceccarelli, S. Pagnotta, F. Uliano, R. Tremigliozzi, G. Condorelli, V. Trimarco, $\mathrm{G}$. Iaccarino, The possible role of chromosome X variability in hypertensive familiarity, J. Hum. Hypertens. (2016), in press.

[54] N. Begum, W. Shen, V. Manganiello, Role of PDE3A in regulation of cell cycle progression in mouse vascular smooth muscle cells and oocytes: implications in cardiovascular diseases and infertility, Curr. Opin. Pharmacol. 11 (6) (2011) 725-729.

[55] S. Lavi, O. Nevo, I. Thaler, R. Rosenfeld, L. Dayan, N. Hirshoren, L. Gepstein, G. Jacob, Effect of aging on the cardiovascular regulatory systems in healthy women, Am. J. Physiol. Regul. Integr. Comp. Physiol. 292 (2) (2007) R788-R793.

[56] A. Menotti, M. Lanti, M. Mancini, A. Zanchetti, M. Laurenzi, O. Terradura Vagnarelli, P. Puddu, Moderate leisure time physical activity and occurrence of cardiovascular events: a 10-year follow-up in the gubbio population study, J. Cardiovasc. Dis. 2 (5) (2014) 218-224.

[57] A.J. Ross, Z. Gao, J.P. Pollock, U.A. Leuenberger, L.I. Sinoway, M.D. Muller, Beta-adrenergic receptor blockade impairs coronary exercise hyperemia in young men but not older men, Am. J. Physiol. Heart Circ. Physiol. 307 (10) (2014) H1497-H1503

[58] C.J. Huang, A.L. Slusher, M. Whitehurst, M. Wells, J.T. Mock, A. Maharaj, Y. Shibata, Acute aerobic exercise mediates G protein-coupled receptor kinase 2 expression in human PBMCs, Life Sci. 135 (2015) 87-91.

[59] A. Maffei, C. Vecchione, A. Aretini, R. Poulet, U. Bettarini, M.T. Gentile, G. Cifelli, G. Lembo, Characterization of nitric oxide release by nebivolol and its metabolites, Am. J. Hypertens. 19 (6) (2006) 579-586.
[60] A. Maffei, G. Lembo, Nitric oxide mechanisms of nebivolol, Ther. Adv. Cardiovasc. Dis. 3 (4) (2009) 317-327.

[61] R. De Rosa, G. Galasso, F. Piscione, G. Santulli, A. Pierri, D. Sorriento, G. Iaccarino, B. Trimarco, M. Chiariello, Beta2-adrenergic receptor improves the endothelial progenitor cells angiogenic function, Eur. Heart J. 30 (S1) (2013) 353 .

[62] M. Ciccarelli, D. Sorriento, E. Cipolletta, G. Santulli, A. Fusco, R.H. Zhou, A.D. Eckhart, K. Peppel, W.J. Koch, B. Trimarco, G. Iaccarino, Impaired neoangiogenesis in beta(2)-adrenoceptor gene-deficient mice: restoration by intravascular human beta(2)-adrenoceptor gene transfer and role of NFkappaB and CREB transcription factors, Br. J. Pharmacol. 162 (3) (2011) $712-721$

[63] M. Ciccarelli, G. Santulli, V. Pascale, B. Trimarco, G. Iaccarino, Adrenergic receptors and metabolism: role in development of cardiovascular disease, Front. Physiol. 4 (2013) 265.

[64] G. Santulli, M. Ciccarelli, B. Trimarco, G. Iaccarino, Physical activity ameliorates cardiovascular health in elderly subjects: the functional role of the beta adrenergic system, Front. Physiol. 4 (2013) 209.

[65] D. Sorriento, G. Santulli, A. Franco, E. Cipolletta, L. Napolitano, J. Gambardella, I. Gomez-Monterrey, P. Campiglia, B. Trimarco, G. Iaccarino, M. Ciccarelli, Integrating GRK2 and NFkappaB in the pathophysiology of cardiac hypertrophy, J. Cardiovasc. Trans. Res. 8 (8) (2015) 493-502.

[66] D. Czuriga, W.J. Paulus, I. Czuriga, I. Edes, Z. Papp, A. Borbely, Cellular mechanisms for diastolic dysfunction in the human heart, Curr. Pharm. Biotechnol. 13 (13) (2012) 2532-2538.

[67] W. Xie, G. Santulli, S.R. Reiken, Q. Yuan, B.W. Osborne, B.X. Chen, A.R. Marks, Mitochondrial oxidative stress promotes atrial fibrillation, Sci. Rep. 5 (2015) 11427.

[68] G. Santulli, G. Iaccarino, N. De Luca, B. Trimarco, G. Condorelli, Atrial fibrillation and microRNAs, Front. Physiol. 5 (2014) 15

[69] S.L. D’Ascia, C. D’Ascia, V. Marino, A. Lombardi, R. Santulli, M. Chiariello, G. Santulli, Cardiac resynchronisation therapy response predicts occurrence of atrial fibrillation in non-ischaemic dilated cardiomyopathy, Int. J. Clin. Pract. 65 (11) (2011) 1149-1155

[70] G. Santulli, S.L. D'Ascia, C. D'Ascia, Development of atrial fibrillation in recipients of cardiac resynchronization therapy: the role of atrial reverse remodelling, Can. J. Cardiol. 28 (2) (2012), 245 e17.

[71] F. Lanni, G. Santulli, R. Izzo, S. Rubattu, B. Zanda, M. Volpe, G. Iaccarino, B. Trimarco, The $\mathrm{Pl}(\mathrm{A} 1 / \mathrm{A} 2)$ polymorphism of glycoprotein IIIa and cerebrovascular events in hypertension: increased risk of ischemic stroke in high-risk patients, J. Hypertens. 25 (3) (2007) 551-556.

[72] D. Sorriento, G. Santulli, A. Fusco, A. Anastasio, B. Trimarco, G. Iaccarino, Intracardiac injection of AdGRK5-NT reduces left ventricular hypertrophy by inhibiting NF-kappaB-dependent hypertrophic gene expression, Hypertension 56 (4) (2010) 696-704

[73] P.S. Hees, J.L. Fleg, E.G. Lakatta, E.P. Shapiro, Left ventricular remodeling with age in normal men versus women: novel insights using three-dimensional magnetic resonance imaging, Am. J. Cardiol. 90 (11) (2002) 1231-1236.

[74] C. Cantini, P. Kieffer, B. Corman, P. Liminana, J. Atkinson, I. Lartaud-Idjouadiene, Aminoguanidine and aortic wall mechanics, structure, and composition in aged rats, Hypertension 38 (4) (2001) 943-948.

[75] G. Iaccarino, M. Ciccarelli, D. Sorriento, E. Cipolletta, V. Cerullo, G.L. Iovino, A Paudice, A. Elia, G. Santulli, A. Campanile, O. Arcucci, L. Pastore, F. Salvatore, G. Condorelli, B. Trimarco, AKT participates in endothelial dysfunction in hypertension, Circulation 109 (21) (2004) 2587-2593

[76] G. Santulli, G. Pagano, C. Sardu, W. Xie, S. Reiken, S.L. D’Ascia, M. Cannone, N Marziliano, B. Trimarco, T.A. Guise, A. Lacampagne, A.R. Marks, Calcium release channel RyR2 regulates insulin release and glucose homeostasis, J. Clin. Invest. 125 (5) (2015) 1968-1978.

[77] I. Heinonen, M. Wendelin-Saarenhovi, K. Kaskinoro, J. Knuuti, M. Scheinin, K.K. Kalliokoski, Inhibition of alpha-adrenergic tone disturbs the distribution of blood flow in the exercising human limb, Am. J. Physiol. Heart Circ. Physiol. 305 (2) (2013) H163-H172.

[78] A. Perino, A. Ghigo, E. Ferrero, F. Morello, G. Santulli, G.S. Baillie, F. Damilano, A.J. Dunlop, C. Pawson, R. Walser, R. Levi, F. Altruda, L. Silengo, L.K. Langeberg, G. Neubauer, S. Heymans, G. Lembo, M.P. Wymann, R. Wetzker, M.D. Houslay, G. Iaccarino, J.D. Scott, E. Hirsch, Integrating cardiac PIP3 and cAMP signaling through a PKA anchoring function of p110gamma, Mol. Cell 42 (1) (2011) 84-95.

[79] L. Wu, L. Liu, Systematic review and meta-analysis evaluating the impact of vitamin $\mathrm{D}$ on the risk of heart failure: new evidence from population-based studies, J. Cardiovasc. Dis. 2 (3) (2014) 159-173.

[80] H. Al Maluli, C. DeStephan, Hemodynamic monitoring in the intensive care unit, J. Cardiovasc. Dis. 2 (2) (2014) 101-115.

[81] C. Sardu, R. Marfella, G. Santulli, G. Paolisso, Functional role of miRNA in cardiac resynchronization therapy, Pharmacogenomics 15 (8) (2014) 1159-1168.

[82] M.N. Nguyen, H. Kiriazis, D. Ruggiero, X.M. Gao, Y. Su, A. Jian, L.P. Han, J.R McMullen, X.J. Du, Spontaneous ventricular tachyarrhythmias in beta2-adrenoceptor transgenic mice in relation to cardiac interstitial fibrosis, Am. J. Physiol. Heart Circ. Physiol. 309 (5) (2015) H946-H947.

[83] R.H. Ritchie, C.H. Leo, C. Qin, E.J. Stephenson, M.A. Bowden, K.D. Buxton, S.] Lessard, D.A. Rivas, L.G. Koch, S.L. Britton, J.A. Hawley, O.L. Woodman, Low intrinsic exercise capacity in rats predisposes to age-dependent cardiac remodeling independent of macrovascular function, Am. J. Physiol. Heart Circ. Physiol. 304 (5) (2013) H729-H739. 
[84] D. Ho, L. Yan, K. Iwatsubo, D.E. Vatner, S.F. Vatner, Modulation of beta-adrenergic receptor signaling in heart failure and longevity: targeting adenylyl cyclase type 5, Heart Fail. Rev. 15 (5) (2010) 495-512.

[85] G.W. Dorn 2nd, N.M. Tepe, J.N. Lorenz, W.J. Koch, S.B. Liggett, Low- and high-level transgenic expression of beta2-adrenergic receptors differentially affect cardiac hypertrophy and function in Galphaq-overexpressing mice, Proc. Natl. Acad. Sci. U.S.A. 96 (11) (1999) 6400-6405.

[86] H.T. Tevaearai, A.D. Eckhart, G.B. Walton, J.R. Keys, K. Wilson, W.J. Koch, Myocardial gene transfer and overexpression of beta2-adrenergic receptors potentiates the functional recovery of unloaded failing hearts, Circulation 106 (1) (2002) 124-129.

[87] S. Engelhardt, L. Hein, F. Wiesmann, M.J. Lohse, Progressive hypertrophy and heart failure in beta1-adrenergic receptor transgenic mice, Proc. Natl. Acad. Sci. U.S.A. 96 (12) (1999) 7059-7064

[88] X.J. Du, X.M. Gao, B. Wang, G.L. Jennings, E.A. Woodcock, A.M. Dart, Age-dependent cardiomyopathy and heart failure phenotype in mice overexpressing beta(2)-adrenergic receptors in the heart, Cardiovasc. Res. 48 (3) (2000) 448-454

[89] A. Lymperopoulos, S. Chowdhary, K. Sankar, I. Simon, Regulation of catecholamine production from the adrenal medulla, in: G. Santulli (Ed.), Adrenal Glands: From Pathophysiology to Clinical Evidence, Nova Science Publisher, New York, NY, 2015

[90] J. Thireau, S. Karam, S. Roberge, J. Roussel, F. Aimond, C. Cassan, A. Gac, D. Babuty, J.Y. Le Guennec, A. Lacampagne, J. Fauconnier, S. Richard, Beta-adrenergic blockade combined with subcutaneous B-type natriuretic peptide: a promising approach to reduce ventricular arrhythmia in heart failure? Heart 100 (11) (2014) 833-841.

[91] K.S. Shiny, S.H. Kumar, K.H. Farvin, R. Anandan, K. Devadasan, Protective effect of taurine on myocardial antioxidant status in isoprenaline-induced myocardial infarction in rats, J. Pharm. Pharmacol. 57 (10) (2005) 1313-1317.

[92] C.J. Huang, H.E. Webb, M.C. Zourdos, E.O. Acevedo, Cardiovascular reactivity, stress, and physical activity, Front. Physiol. 4 (2013) 314

[93] T.P. Weng, T.C. Fu, C.H. Wang, C.C. Hsu, J.S. Wang, Activation of lymphocyte autophagy/apoptosis reflects haemodynamic inefficiency and functional aerobic impairment in patients with heart failure, Clin. Sci. 127 (10) (2014) 589-602.

[94] A. Berezin, A. Kremzer, T. Samura, Y. Martovitskaya, Apoptotic microparticles to progenitor mononuclear cells ratio in heart failure: relevance of clinical status and outcomes, J. Cardiovasc. Dis. 2 (2) (2014) $50-57$

[95] M. Ciccarelli, G. Santulli, A. Campanile, G. Galasso, P. Cervero, G.G. Altobelli, V. Cimini, L. Pastore, F. Piscione, B. Trimarco, G. Iaccarino, Endothelial alpha1-adrenoceptors regulate neo-angiogenesis, Br. J. Pharmacol. 153 (5) (2008) 936-946.

[96] N. Buroker, ADRBK1 (GRK2) rSNPs transcriptional factor binding sites and cardiovascular disease in the black population, J. Cardiovasc. Dis. 2 (2) (2014) 62-67

[97] G. Santulli, Epidemiology of cardiovascular disease in the 21st century: updated numbers and updated facts, J. Cardiovasc. Dis. 1 (1) (2013) 1-2.

[98] L.H. Philipson, Beta-agonists and metabolism, J. Allergy Clin. Immunol. 110 (6 Suppl) (2002) S313-7.

[99] R.A. Ngala, J. O’Dowd, S.J. Wang, A. Agarwal, C. Stocker, M.A. Cawthorne, J.R Arch, Metabolic responses to BRL37344 and clenbuterol in soleus muscle and $\mathrm{C2C12}$ cells via different atypical pharmacologies and beta2-adrenoceptor mechanisms, Br. J. Pharmacol. 155 (3) (2008) 395-406.

[100] K. Sakamoto, G.D. Holman, Emerging role for AS160/TBC1D4 and TBC1D1 in the regulation of GLUT4 traffic, Am. J. Physiol. 295 (1) (2008) E29-E37.

[101] S.J. Maarbjerg, L. Sylow, E.A. Richter, Current understanding of increased insulin sensitivity after exercise-emerging candidates, Acta Physiol. (Oxford England) 202 (3) (2011) 323-335.

[102] J. Perez-Schindler, A. Philp, K. Baar, J. Hernandez-Cascales, Regulation of contractility and metabolic signaling by the beta2-adrenergic receptor in rat ventricular muscle, Life Sci. 88 (19-20) (2011) 892-897.

[103] A. Bruzzone, A. Sauliere, F. Finana, J.M. Senard, I. Luthy, C. Gales, Dosage-dependent regulation of cell proliferation and adhesion through dual beta2-adrenergic receptor/cAMP signals, FASEB J. 28 (3) (2014) $1342-1354$.

[104] D.G. Hardie, F.A. Ross, S.A. Hawley, AMPK: a nutrient and energy sensor that maintains energy homeostasis, Nat. Rev. 13 (4) (2012) 251-262.

[105] L.A. Nikolaidis, I. Poornima, P. Parikh, M. Magovern, Y.T. Shen, R.P. Shannon, The effects of combined versus selective adrenergic blockade on left ventricular and systemic hemodynamics, myocardial substrate preference, and regional perfusion in conscious dogs with dilated cardiomyopathy, J. Am. Coll. Cardiol. 47 (9) (2006) 1871-1881.

[106] G. Shahid, T. Hussain, GRK2 negatively regulates glycogen synthesis in mouse liver FL83B cells, J. Biol. Chem. 282 (28) (2007) 20612-20620.

[107] J.R. Lupien, M.F. Hirshman, E.S. Horton, Effects of norepinephrine infusion on in vivo insulin sensitivity and responsiveness, Am. J. Physiol. 259 (2 Pt 1) (1990) E210-E215

[108] N.E. Straznicky, M.T. Grima, C.I. Sari, N. Eikelis, E.A. Lambert, P.J. Nestel, M.D. Esler, J.B. Dixon, R. Chopra, A.J. Tilbrook, M.P. Schlaich, G.W. Lambert, Neuroadrenergic dysfunction along the diabetes continuum: a comparative study in obese metabolic syndrome subjects, Diabetes 61 (10)(2012) 2506-2516.
[109] on behalf of the Toronto Consensus Panel on DiabeticV. Spallone, D. Ziegler, R. Freeman, L. Bernardi, S. Frontoni, R. Pop-Busui, M. Stevens, P. Kempler, J. Hilsted, S. Tesfaye, P. Low, P. Valensi, Cardiovascular autonomic neuropathy in diabetes: clinical impact, assessment, diagnosis, and management, Diabetes Metab. Res. Rev. (2011).

[110] M.J. Quinones, S.B. Nicholas, C.J. Lyon, Insulin resistance and the endothelium, Curr. Diab. Rep. 5 (4) (2005) 246-253.

[111] N.E. Straznicky, E.A. Lambert, P.J. Nestel, M.T. McGrane, T. Dawood, M.P. Schlaich, K. Masuo, N. Eikelis, B. de Courten, J.A. Mariani, M.D. Esler, F. Socratous, R. Chopra, C.I. Sari, E. Paul, G.W. Lambert, Sympathetic neural adaptation to hypocaloric diet with or without exercise training in obese metabolic syndrome subjects, Diabetes 59 (1) (2010) 71-79.

[112] F. Oriente, S. Iovino, A. Cassese, C. Romano, C. Miele, G. Troncone, M. Balletta A. Perfetti, G. Santulli, G. Iaccarino, R. Valentino, F. Beguinot, P. Formisano, Overproduction of phosphoprotein enriched in diabetes (PED) induces mesangial expansion and upregulates protein kinase C-beta activity and TGF-beta1 expression, Diabetologia 52 (12) (2009) 2642-2652.

[113] G. Schernthaner, Pleiotropic effects of thiazolidinediones on traditional and non-traditional atherosclerotic risk factors, Int. J. Clin. Pract. 63 (6) (2009) 912-929.

[114] Q. Fu, B. Xu, Y. Liu, D. Parikh, J. Li, Y. Li, Y. Zhang, C. Riehle, Y. Zhu, T. Rawlings, Q. Shi, R.B. Clark, X. Chen, E.D. Abel, Y.K. Xiang, Insulin inhibits cardiac contractility by inducing a Gi-biased beta2 adrenergic signaling in hearts, Diabetes (2014)

[115] J.J. Wright, J. Kim, J. Buchanan, S. Boudina, S. Sena, K. Bakirtzi, O. Ilkun, H.A. Theobald, R.C. Cooksey, K.V. Kandror, E.D. Abel, Mechanisms for increased myocardial fatty acid utilization following short-term high-fat feeding, Cardiovasc. Res. 82 (2) (2009) 351-360.

[116] P.S. Azevedo, M.F. Minicucci, P.P. Santos, S.A. Paiva, L.A. Zornoff, Energy metabolism in cardiac remodeling and heart failure, Cardiol. Rev. 21 (3) (2013) 135-140.

[117] J.F. Glatz, J.J. Luiken, A. Bonen, Membrane fatty acid transporters as regulators of lipid metabolism: implications for metabolic disease, Physiol. Rev. 90 (1) (2010) 367-417.

[118] I. Shimizu, T. Minamino, H. Toko, S. Okada, H. Ikeda, N. Yasuda, K. Tateno, J. Moriya, M. Yokoyama, A. Nojima, G.Y. Koh, H. Akazawa, I. Shiojima, C.R. Kahn, E.D. Abel, I. Komuro, Excessive cardiac insulin signaling exacerbates systolic dysfunction induced by pressure overload in rodents, J. Clin. Invest. 120 (5) (2010) 1506-1514.

[119] M.S. Avendano, E. Lucas, M. Jurado-Pueyo, S. Martinez-Revelles, R. Vila-Bedmar, F. Mayor, M. Salaices Jr., A.M. Briones, C. Murga, Increased nitric oxide bioavailability in adult GRK2 hemizygous mice protects against angiotensin II-induced hypertension, Hypertension 63 (2) (2014) 369-375.

[120] E. Cipolletta, A. Campanile, G. Santulli, E. Sanzari, D. Leosco, P. Campiglia, B Trimarco, G. Iaccarino, The G protein coupled receptor kinase 2 plays an essential role in beta-adrenergic receptor-induced insulin resistance, Cardiovasc. Res. 84 (3) (2009) 407-415

[121] K. Watari, M. Nakaya, H. Kurose, Multiple functions of G protein-coupled receptor kinases, J. Mol. Signal. 9 (1) (2014) 1

[122] A. Fusco, G. Santulli, D. Sorriento, E. Cipolletta, C. Garbi, G.W. Dorn2nd, B. Trimarco, A. Feliciello, G. Iaccarino, Mitochondrial localization unveils a novel role for GRK2 in organelle biogenesis, Cell. Signal. 24 (2) (2012) $468-475$.

[123] M. Chen, P.Y. Sato, J.K. Chuprun, R.J. Peroutka, N.J. Otis, J. Ibetti, S. Pan, S.S Sheu, E. Gao, W.J. Koch, Prodeath signaling of G protein-coupled receptor kinase 2 in cardiac myocytes after ischemic stress occurs via extracellular signal-regulated kinase-dependent heat shock protein 90-mediated mitochondrial targeting, Circ. Res. 112 (8) (2013) 1121-1134.

[124] D. Sorriento, M. Ciccarelli, G. Santulli, M. Illario, B. Trimarco, G. Iaccarino, Trafficking GRK2: cellular and metabolic consequences of GRK2 subcellular localization, Transl. Med. UniSa 10 (2014) 3-7.

[125] L.Y. Lin, C.K. Wu, J.M. Juang, Y.C. Wang, M.Y. Su, L.P. Lai, J.J. Hwang, F.T Chiang, W.Y. Tseng, J.L. Lin, Myocardial regional interstitial fibrosis is associated with left intra-Ventricular dyssynchrony in patients with heart failure: a cardiovascular magnetic resonance study, Sci. Rep. 6 (2016) 20711.

[126] J. Trial, M.L. Entman, K.A. Cieslik, Mesenchymal stem cell-derived inflammatory fibroblasts mediate interstitial fibrosis in the aging heart, J. Mol. Cell. Cardiol. 91 (2016) 28-34.

[127] E.B. Schelbert, K.M. Piehler, K.M. Zareba, J.C. Moon, M. Ugander, D.R. Messroghli, U.S. Valeti, C.C. Chang, S.G. Shroff, J. Diez, C.A. Miller, M. Schmitt, P. Kellman, J. Butler, M. Gheorghiade, T.C. Wong, Myocardial fibrosis quantified by extracellular volume is associated with subsequent hospitalization for heart failure, death, or both across the spectrum of ejection fraction and heart failure stage, J. Am. Heart Assoc. 4 (12) (2015).

[128] D.F. Dai, P.S. Rabinovitch, Cardiac aging in mice and humans: the role of mitochondrial oxidative stress, Trends Cardiovasc. Med. 19 (7) (2009) 213-220.

[129] M.A. Horn, A.W. Trafford, Aging and the cardiac collagen matrix: novel mediators of fibrotic remodelling, J. Mol. Cell. Cardiol. (2015), in press.

[130] Y. Iwanaga, T. Aoyama, Y. Kihara, Y. Onozawa, T. Yoneda, S. Sasayama, Excessive activation of matrix metalloproteinases coincides with left ventricular remodeling during transition from hypertrophy to heart failure in hypertensive rats, J. Am. Coll. Cardiol. 39 (8) (2002) 1384-1391.

[131] U. Seeland, S. Selejan, S. Engelhardt, P. Muller, M.J. Lohse, M. Bohm, Interstitial remodeling in beta1-adrenergic receptor transgenic mice, Basic Res. Cardiol. 102 (2) (2007) 183-193. 
[132] S. Kato, F.G. Spinale, R. Tanaka, W. Johnson, G.t. Cooper, M.R. Zile, Inhibition of collagen cross-linking: effects on fibrillar collagen and ventricular diastolic function, Am. J. Physiol. 269 (3 Pt 2) (1995) H863-H868.

[133] C. Communal, M. Singh, B. Menon, Z. Xie, W.S. Colucci, K. Singh, beta1 integrins expression in adult rat ventricular myocytes and its role in the regulation of beta-adrenergic receptor-stimulated apoptosis, J. Cell. Biochem. 89 (2) (2003) 381-388.
[134] C. Banfi, V. Cavalca, F. Veglia, M. Brioschi, S. Barcella, L. Mussoni, L. Boccotti, E. Tremoli, P. Biglioli, P. Agostoni, Neurohormonal activation is associated with increased levels of plasma matrix metalloproteinase-2 in human heart failure, Eur. Heart J. 26 (5) (2005) 481-488.

Please cite this article in press as: G. Santulli, G. Iaccarino, Adrenergic signaling in heart failure and cardiovascular aging, Maturitas (2016), http://dx.doi.org/10.1016/j.maturitas.2016.03.022 